\title{
O amor nos tempos do Tinder: Uma análise dos relacionamentos amorosos na contemporaneidade a partir da compreensão de adultos e jovens adultos
}

\section{Love in times of Tinder: An analysis of love relationships in contemporaneity through the eyes of adults and young adults}

\author{
El amor en los tiempos de Tinder: Un análisis de las relaciones \\ de amor en la sociedad contemporánea de la comprensión de \\ los adultos y adultos jóvenes
}

\author{
Marcio Acselrad* \\ Universidade de Fortaleza - UNIFOR, Fortaleza, Ceará, Brasil
}

\author{
Rafaelly Rocha Lima Barbosa** \\ Universidade de Fortaleza - UNIFOR, Fortaleza, Ceará, Brasil
}

\begin{abstract}
RESUMO
Em uma sociedade marcada pela efemeridade, descarte e fluidez, os relacionamentos amorosos passaram a ser afetados por estes predicados. $\mathrm{Na}$ era do amor líquido e dos relacionamentos virtuais, os indivíduos passam a manter vínculos afrouxados a fim de desfazê-los rapidamente. Partindo desta premissa, o presente estudo buscou comparar o discurso de pessoas com idade entre 20 e 25 anos com o de pessoas com idade entre 40 e 45 anos. A metodologia utilizada foi a pesquisa qualitativa, com uso de entrevistas semiestruturadas realizadas com oito participantes. Para a interpretação e compreensão dos dados obtidos fez-se uso da análise do conteúdo de Bardin. Pudemos concluir que a faixa etária é um fator relevante na consideração dos relacionamentos amorosos na contemporaneidade e que a dita liquidez dos relacionamentos não é avaliada da mesma forma por todos os indivíduos considerados no estudo.
\end{abstract}

Palavras-chave: amor, relacionamentos, contemporaneidade, virtual.

\begin{abstract}
In a society marked by volatility and fluidity, relationships are also being affected by those predicates. Love in modern society is liquid and virtual, attributes that cause individuals to keep loosened links in order to undo them quickly. Therefore, the present study sought to compare the speech of people aged between 20 and 25 years with people aged between 40 and 45 years. The methodology used was a qualitative research with the use of semi-structured interviews conducted with eight participants. Interpretation and understanding of the data obtained was made using Bardin's content analysis. We concluded that age is a relevant factor in considering relationships nowadays and that not all the people interviewed face such liquidity in relationships the same way.
\end{abstract}


Key-words: love, relationships, contemporaneity, virtuality.

\begin{abstract}
RESUMEN
En una sociedad marcada por la fugacidad, el descarte y la fluidez, las relaciones fueron afectadas por estos predicados. El amor en la sociedad moderna se presenta líquido y virtual, atributos que hacen que los individuos mantengan enlaces flojos para deshacerlos rápidamente. Así, el presente estudio intentó comparar el discurso de personas de entre 20 y 25 años con personas de entre 40 y 45 años. La metodología utilizada fue la investigación cualitativa con el uso de entrevistas semiestructuradas realizadas con ocho participantes. La interpretación y comprensión de los datos obtenidos se realizó utilizando el análisis de contenido de Bardin. Concluimos que la edad es un factor relevante en la consideración de los relacionamientos amorosos en la contemporaneidad y que la dita liquidez de los relacionamientos no es considerada de la misma forma por todos os individuos considerados en el estudio.
\end{abstract}

Palabras clave: amor, relacionamientos, contemporaneidad, virtualidad.

\title{
1 Introdução
}

"Beijar cem pessoas em um dia" e "já havia conquistado 33 mulheres em menos de duas horas". Ambas as frases foram retiradas de uma matéria publicada no G1 intitulada "Jovens tem até meta para beijar na boca em point na Festa do Peão". A notícia denota o quanto o fenômeno denominado de 'ficar' tornou-se comum entre as pessoas na atualidade. A partir dela é possível perceber que, dada a possibilidade de se estabelecer um relacionamento com várias pessoas em um mesmo dia, o modo de se estabelecer um vínculo amoroso está passando por transformações bastante radicais e intensas. Desta forma, a Psicologia não pode se furtar a debruçar-se sobre o tema.

Compreende-se que o conceito de amor é um processo construído ao longo do tempo a partir de um contexto social, histórico, religioso, cultural, econômico e político. Diante disso, percebe-se uma série de estudos que se debruçaram a problematizar as alterações que as práticas amorosas sofreram no decorrer da história (Bauman, 2004; Chaves, 2001; Costa, 1998; Giddens, 1993). Também é possível encontrar estudos que visam problematizar questões mais contemporâneas sobre o assunto, tais como, os relacionamentos amorosos e a tecnologia (A. S. M. Dela Coleta, Dela Coleta \& Guimarães, 2008) e estudos empíricos sobre relacionamentos entre jovens (Chaves, 2010; Chaves, 2016). Outro estudo na área foi o de Schlosser e Camargo (2014), os autores visaram fazer um levantamento sobre as pesquisas que ocorreram com a temática do amor e relacionamentos amorosos, datados de 2002 a 2012.

Entre os muitos autores que discorrem sobre o amor, encontramos Simmel (1909/1993) em sua Filosofia do amor e Barthes 
(1977/2003) com seu Fragmentos de um discurso amoroso. De acordo com Georg Simmel (1909/1993) o sentimento do amor tem uma associação direta com o objeto amado. Assim a pessoa que ama passa a compreender que sua vida é unicamente mediada pelo amor de seu amado. O sujeito nessa condição, afirma, objetiva unir-se ao amado a fim de tornarem-se uma única pessoa. Assim, Simmel analisa o amor a partir de uma paradoxal visão do egoísmo e da dependência, uma vida movida pela alteridade e pela heteronomia, visto que nossa felicidade, atrelada exclusivamente á presença do amor, é mercê do amor do outro, que pode ou não corresponder ao nosso.

Já para o semiólogo Rolland Barthes (1977/2003) no amor há um processo de anulação pessoal dos amantes, em que dois se tornam um. Alerta também para a solidão do discurso amoroso na atualidade, das cartas de amor, por exemplo, atropeladas por outros discursos, primordialmente o discurso científico, hipertrofiado e hipervalorizado. Walter Benjamin (1994) é outro que irá lamentar a perda do poder do narrador romântico, sobrepujado pelo efervescente mundo das informações midiáticas. Percebe-se claramente a diferença e o contraste existentes entre a concepção de amor dos autores, apresentado como a fusão de dois corpos em um e a constituição de uma subjetividade partilhada a dois, com a noção de liquidez dos relacionamentos contemporâneos, em que não se busca necessariamente este ideal, mas antes temos a visão de relacionamentos efêmeros e hedonistas.

Sobre a questão do amor, Freud cita, em Mal-estar na Civilização, que esta é a forma do homem de atender ao princípio do prazer, ou seja, é uma das maneiras que este tem de encontrar a felicidade. Contudo, é diante disso que este passa a ser visto por meio de uma eficácia limitada, pois a ausência do objeto de amor deixa o sujeito no desamparo. Isso é notavelmente percebido já que o sujeito nunca está tanto indefeso contra o sofrimento quanto ao fato de estar amando; e nunca se encontra tão desamparadamente infeliz do que quando perde seu objeto de amor ou não é correspondido, como no caso do jovem Werther, criado por Goethe (1774/2009), e de tantos outros.

Costa (1998) tem uma concepção similar ao retratar que o amor pode tanto ser fruto de felicidade quanto fonte de profundo sofrimento. Percebe-se então que o indivíduo tem uma necessidade de amar e, simultaneamente, um receio de se ferir. A estratégia contemporânea passa a ser o estabelecimento de um prazo de validade pré-determinado, um amor com data de vencimento já estabelecida, esses relacionamentos líquidos acabam sendo marcados por encontros de sexo casuais que recebem a denominação de "fazer amor" (Carvalho, 2010; Bauman, 2004). 
Uma autora em particular lança luzes bastante peculiares sobre o assunto, muito antes que pudéssemos imaginar viver no mundo líquido e volátil apontado por Bauman. Para AynRand, romancista e teórica de um pragmatismo ultra-radical, musa do movimento chamado de libertarismo ou objetivismo, o amor nada mais é do que uma transação como outra qualquer. Tal tese pode ser encontrada, por exemplo, em A revolta de Atlas, publicado em 1957 (Rand, 2012). À visão altruísta que encara o amor como doação, renúncia, algo que estaria acima dos interesses pessoais ou mesmo como ferramenta de perpetuação da espécie, Rand contrapõe a noção de que o ser humano é essencialmente egoísta e solitário e que deve fazer todo o possível para atingir a felicidade pessoal, independente de qualquer outra variável (incluindo, evidentemente, o amor ou a consideração do outro).

Percebe-se como tal ideia pragmática e objetificante das relações humanas é o terreno ideal para que frutifique a noção de que relações, inclusive as amorosas, são contratos com um objetivo específico a se cumprir e que, caso o combinado não se cumpra, possam ser imediatamente desfeitos. É o que o sociólogo Ferdinad Tönnies (Tönies, 1887/1957 citado por Defleur \& Ball-Rokeach, 1993) denominara a passagem do elo comunitário e tradicional (Gemmeinshaft), em que vigoram relações clânicas, filiais, sanguíneas e em que o lastro social é a palavra para o elo societário e moderno (Gesselschaft), típico do mundo industrial, em que relações anônimas passam a prevalecer (Tönies, 1887/1957 citado por Defleur \& Ball-Rokeach, 1993). Neste caso, o lastro há de ser o contrato. Tais relações, que nascem do mundo do comércio e dos negócios não, tardaram a invadir a esfera privada, reconfigurando para sempre o que se costumava chamar de casamento.

Tendo isso em mente, passamos a nos questionar: Como se constituem os relacionamentos amorosos na contemporaneidade? Que mudanças subjetivas somos capazes de identificar? Como analisar e problematizar questões associadas aos relacionamentos amorosos na contemporaneidade? Neste sentido acreditamos que um importante meio de acesso a tais informações seria dando voz aos sujeitos em questão. Para tanto, realizamos uma série de entrevistas semiestruturadas com oito estudantes de graduação, com faixa etária entre 20 e 25 anos e outros entre 40 e 45 anos de uma universidade particular da cidade de Fortaleza. O objetivo era o de levantar dados sobre a forma como estes compreendem os relacionamentos amorosos atualmente. Para tanto foram investigadas questões relacionadas ao fenômeno do ficar, ao namoro, amor, questões de gênero, casamento, e amor virtual. O aplicativo Tinder, cujo objetivo é a busca de possíveis parceiros para relacionamentos muitas vezes fugazes, embora não seja o foco da pesquisa, aparece no título do trabalho como forma de tentar definir a época em que vivemos, em 
que fenômenos como a corte, o amor romântico e o enamoramento são muitas vezes substituídas por cliques em um aparelho celular. Para melhor facilitar o entendimento, torna-se necessário discorrer sobre questões pertinentes aos relacionamentos na contemporaneidade. A atual sociedade, que Bauman (2008) denomina de modernidade líquida, tem como característica a eliminação das divisões entre consumidor e mercadoria, de tal modo que o consumidor passa a ser um objeto consumido além de também ser percebida uma constante fluidez, efemeridade e o rápido descarte. Assim, segundo o autor os relacionamentos amorosos também acabam sendo perpassados por essas características citadas: consumimo-nos uns aos outros da mesma forma precária e volátil que consumimos bens e serviços.

Bauman (2004) ao falar dos relacionamentos amorosos, os descreve como uma mercadoria a ser consumida: "guiada pelo impulso [...] tal como outros bens de consumo, ela deve ser consumida instantaneamente (não requer maiores treinamentos nem uma preparação prolongada) e usada uma só vez, 'sem preconceito'. É, antes de mais nada, eminentemente descartável" (p. 27). O autor ainda reitera que os relacionamentos 'novos e aperfeiçoados', 'de comprometimento ligh', reduzem seu tempo de duração para que ele seja o mesmo da satisfação que produzem: o compromisso é válido até que a satisfação desapareça ou caia abaixo de um padrão aceitável - e nem um instante a mais (Bauman, 2009, p. 26).

É importante ressaltar, no entanto, que as teorias de Bauman correm um risco sempre presente em qualquer aporte teórico: o da excessiva generalização. Não se deve, portanto, considerar suas ideias como verdades absolutas e nem mesmo como uma chave de compreensão para todo e qualquer relacionamento contemporâneo. $O$ objetivo aqui é perceber uma tendência, um fenômeno que aparece na contemporaneidade e que chama a nossa atenção. Mas não podemos perder de vista que nem todos os relacionamentos atuais se encaixam nesta grade. Percebemos que a mesma sociedade que cria os aplicativos de relacionamento e que faz e desfaz contratos num piscar de olhos é aquela em que boa parte das pessoas ainda busca um relacionamento duradouro e significativo e em que o ideal de casamento permanece presente no imaginário de boa parte das pessoas. Malgrado o aumento exponencial no número de divórcios e separações, muitas delas acontecidas em questão de semana (ou mesmo dias, no caso de algumas celebridades) ainda é considerável o número de relações estáveis e duradouras.

De acordo com Rougement (2003), a concepção de amor na atualidade mantém diversas características ocidentais e é relativamente recente, surgindo aproximadamente no século XII. Nesse período diversas concepções de amor foram estruturadas e também dissolvidas. Além de estudos teóricos levantados sobre a 
temática, a literatura torna-se uma forma de compreender as narrativas sobre o amor, inclusive na contemporaneidade (Borges, 2004). A partir disso é possível citar clássicos históricos que favorecem essa visão, tais como o mito de Tristão e Isolda, analisado por Rougement (2003) em sua obra A história do amor no ocidente ou Os sofrimentos do Jovem Werther, de Goethe (1774/2009), citado acima. Citado como a causa de diversos suicídios no século XVIII, estes acabaram por acrescentar um grande conhecimento sobre 0 amor e relacionamentos amorosos.

É interessante ressaltar que até os dias atuais a literatura ainda carrega consigo uma ideia de amor forte, duradouro e capaz de enfrentar todos os males, muito associado com a concepção do amor romântico, que mantinha os relacionamentos em seu mais alto grau de 'até que a morte nos separe', conotando assim, uma união eterna e um amor infinito. Essa compreensão que literatura carrega difere um pouco sobre a compreensão que alguns estudiosos trazem sobre o amor, sempre o associando a algo fugaz e passageiro. Contudo, difere das leituras românticas mais tradicionais por incorporar em sua narrativa algo estritamente contemporâneo, o "final feliz" está assegurado a ambos que entram no relacionamento. Os sujeitos não se veem colocando sua segurança em risco na busca de obter "sempre mais prazer e sempre mais aprazível prazer",Bauman (1998, p. 09). Eles sempre se encontram com dois dos bens valiosos na atual sociedade, a liberdade e a segurança. Colocando em pauta as compreensões atuais dos relacionamentos e a concepção da literatura é possível perceber o quanto os relacionamentos amorosos revelam sua singularidade.

"Que não seja imortal, posto que é chama, mas que seja infinito enquanto dure". Vinícius de Moraes (1960) expõe aqui um pensamento capaz de condensar a nova concepção de amor do século $X X$, inaugurada pela possibilidade de separação dos cônjuges, primeiro pelo desquite e depois pelo divórcio. $O$ amor pode até durar, mas se apaga. Mas, tal como a chama, tem que ser vivido em toda a sua plenitude, até queimar-se. Esta frase remente a uma intensidade na vivência do amor romântico, que não será eterno e duradouro, fato que Bauman (2004) compreende como fragilidade dos vínculos amorosos. Percebe-se portanto em Vinícius (tanto na obra quanto na vida), uma profunda fidelidade amorosa: ama-se intensamente, como se o relacionamento fosse deveras infinito, mas quando este termina, há que ser fiel também a este sentimento. Em última instância, o que se ama não é o ser amado, mas antes o próprio amor que se sente. Feito o luto da perda do amor, o/a amante está pronto/a a se aventurar novamente no território bravio da conquista.

Sobre o tema do amor eterno, Bauman ressalta que afinal, a definição romântica do amor como "até que a morte nos separe" está decididamente fora de moda [...] Mas o desaparecimento dessa 
noção significa, inevitavelmente, a facilitação dos testes pelos quais uma experiência deve passar para ser chamada de "amor". Em vez de haver mais pessoas atingindo mais vezes os elevados padrões de amor, esses padrões foram baixados. Como resultado, o conjunto de experiências às quais nos referimos com a palavra amor expandiu-se muito (2004, p. 19).

\section{Método}

\section{Participantes e Instrumentos}

A fim de levantar os dados necessários para alcançar os objetivos em questão, buscou-se fazer o uso da metodologia qualitativa, com o uso de entrevistas semiestruturadas a serem tratadas pelo método da análise de conteúdo de Bardin (2012), que visa à compreensão das relações sociais a partir de amostragens da população (Gerhardt, Ramos, Riquinho \& Santos, 2009). Para tanto, foram escolhidos oito estudantes de graduação da universidade onde a pesquisa foi realizada. Todas as entrevistas foram conduzidas individualmente, sendo solicitada a permissão para que as mesmas fossem gravadas. Questões como classe social, religião ou ocupação profissional não foram utilizados como parâmetros relevantes, vez que o objetivo principal era avaliar a questão da faixa etária como possível variável em relação à percepção dos relacionamentos amorosos.

A idade foi um dado de suma importância para a realização da pesquisa, por ser o presente estudo de cunho comparativo. Desta forma, os participantes foram separados em dois grupos, o primeiro é caracterizado pela numeração 01 e composto por quatro pessoas, dois homens e duas mulheres, com idade entre 20 e 25 anos. $O$ segundo grupo, caracterizado pela numeração 02, ficou organizado da mesma forma, tendo como única modificação a idade dos participantes, situada na faixa entre 40 e 45 anos. A fim de coletar os dados de uma maneira igualitária entre os gêneros optou-se pela divisão exata entre homens e mulheres.

O estado civil dos entrevistados foi perguntado. No primeiro grupo, dentre os homens, havia um solteiro e um namorando e, dentre as mulheres, uma solteira e uma noiva. No segundo grupo, um dos homens estava casado e outro solteiro e, uma mulher casada e outra noiva. Percebe-se então que a grande maioria dos entrevistados estava em um relacionamento sério no momento da pesquisa. Ressalta-se que a orientação sexual não foi levada em consideração. Por ser uma entrevista semiestruturada, foi feito um pequeno roteiro de perguntas para guiar os entrevistadores. Todas as perguntas foram feitas a todos os entrevistados. No total foram realizadas 20 perguntas para cada um dos entrevistados (Ver Apêndice 1). As 
temáticas destas envolvem questões relativas a compreensão dos relacionamentos na contemporaneidade, relacionamentos online, sexo e amor, casamento, questões de gênero, relacionamentos e felicidade.

\section{Tabela 1}

\section{Dados gerais dos participantes}

\begin{tabular}{|l|l|l|}
\hline Participantes & Idade & Sexo \\
\hline (A) & 20 & Masculino \\
\hline (B) & 22 & Masculino \\
\hline (C) & 24 & Ferminino \\
\hline (D) & 25 & Feminino \\
\hline (E) & 42 & Masculino \\
\hline (F) & 43 & Masculino \\
\hline (G) & 40 & Feminino \\
\hline (H) & 40 & Feminino \\
\hline
\end{tabular}

\section{Procedimento}

Em busca de compreender os dados que foram obtidos nas entrevistas, utilizou-se a análise do conteúdo tal como postulada por Bardin (2012), que tem como objetivo interpretar, através de diversas técnicas, o conteúdo das comunicações, cabendo ao pesquisador categorizar as unidades que se repetem no discurso dos entrevistados, gerando assim representações das mesmas (Bardin, 2012; Caregnato \& Mutti, 2006).

\section{Considerações éticas}

A pesquisa foi submetida e aprovada pelo Coética, órgão encarregado pela avaliação das implicações éticas de pesquisas feitas com seres humanos na Universidade de Fortaleza. O parecer consubstanciado foi submetido pela Plataforma Brasil e o número do parecer é 1.242 .450 .

\section{Resultados e Discussão}

A modernidade líquida, de acordo com a perspectiva de Zygmunt Bauman, é marcada pela constante velocidade, efemeridade e movimento, assim os relacionamentos amorosos não fogem deste padrão. Diante dessa constante mudança de cenários, a clamar por identidades múltiplas e fugazes, os sujeitos passam a manter os vínculos frouxos visando que possam ser desfeitos rapidamente, como contratos rescindidos (Bauman, 2004; Bauman, 2001; Lipovetsky, 1989). Nessa concepção de que nada dura e nem é feito para durar, a rapidez com que as pessoas passam a formar laços 
afetivos torna-se proporcional à velocidade com que o desmancham (Zordan, 2010). As características citadas são percebidas nas falas dos participantes da pesquisa onde, de acordo com o entrevistado $B$, os relacionamentos estão "menos sérios. Antigamente a gente tinha todo um ritual para começar um relacionamento, hoje em dia ele começa e termina, começa e termina como se não fosse nada, em sua maioria.". O entrevistado A relata que "elas [as pessoas] encaram os relacionamentos não com muita seriedade ultimamente. É, eu olho para aquela pessoa e pode ser que dure um mês ou não, pode ser que dure uma semana ou mais, um ano". Contudo, todos os entrevistados do grupo 01 trouxeram uma fala bastante naturalizada sobre esse fenômeno, chegando inclusive a confirmar que entram ou entraram em relacionamentos assim.

Esse fato pode ser corroborado a partir das falas deles sobre 0 fenômeno do "ficar". O entrevistado B ressaltou que "é o estágio, um momento de conhecer. É um test drive. Você conhece a pessoa, vai ter os primeiros contatos com a pessoa que pode vir a ser alguém legal na sua vida, ou não." A entrevistada C trouxe um discurso acerca disso, relatando que "ficar não é nada! As vezes eu ficava com uma pessoa por ficar e isso não representava nada". Essas compreensões acerca dos relacionamentos amorosos e do "ficar" podem ser compreendidas através de Bauman (2004), que afirma que os relacionamentos amorosos acabam por ser um investimento como qualquer outro que a pessoa pode realizar, contudo "será que alguma vez the ocorreria fazer juras de lealdade às ações que acabou de adquirir?" (p. 29). O autor ressalta ainda que "apostar todas as suas fichas em um só número é a máxima insensatez!" (p. 78).

Sobre esses aspectos, é percebida uma diferença entre os grupos entrevistados. Na fala do participante $\mathrm{F}$, integrante do grupo 02, é possível perceber que ele compreende que:

(...) os relacionamentos amorosos têm uma influência bastante extrema do modo de vida das pessoas hoje, que está bastante corrido e isso acaba influenciando nos relacionamentos interpessoais. Porque você não tem muito tempo para se dedicar, né, por causa da contingência da vida moderna. Aí isso acaba incidindo de forma negativa.

Já a entrevistada $\mathrm{G}$ relata que:

(...) hoje em dia banalizou muito, eu acho. Hoje em dia, sei lá, o meio cultural e a facilidade para se encontrar pessoas fazem com que não se tenha mais aquele relacionamento de você ficar um tempo, e qualquer briga é motivo para terminar um relacionamento. Eu sou de um tempo em que você tem que conversar né. Mas assim, hoje em dia eu vejo o pessoal, 
poucos os amigos que eu tenho na faixa de 30 anos, tem um relacionamento serio há mais de um ano. Eu acho que banalizou bastante, o casamento está banalizado também.

Sobre essa questão ela ainda afirma que "qualquer briga é motivo para terminar um relacionamento. Eu sou do tempo em que você tem que conversar né", tempo do amor romântico. Pois na modernidade esse ideal é rompido, não há mais o laço indissolúvel (Costa, 1999). $O$ fato de a entrevistada relatar ter poucos amigos que tenham um relacionamento sério há mais de um ano remete à questão de que na contemporaneidade os vínculos vêm sendo afrouxados e apertados constantemente, outro aspecto ligado à fluidez dos laços amorosos (Bauman, 2004).

Com relação ao fenômeno do ficar, foi possível perceber que os integrantes do grupo mais velho denotam certa continuidade a esse processo, não se mostrando muito aptos ao ficar somente naquele momento ou naquela noite. A partir da fala do entrevistado $G$ é possível perceber isso, pois para ele ficar é "o primeiro encontro de muitos outros". Já para a participante $F$, "a partir do momento que você beijou, está ficando. E eu só fico com uma pessoa se tiver atração, eu não fico por ficar ou em uma noite. Tem que rolar um interesse, um papo legal.". É possível perceber como essa concepção mantém uma associação com um relacionamento que representa algo para a pessoa, diferente do que a participante $C$ trouxe: "isso não representava nada".

A participante $\mathrm{H}$ relatou nunca ter ficado com ninguém. Perguntada acerca de sua concepção sobre o "ficar", ela trouxe um discurso de que "então nem sei o que é ficar. Mas, acho que ficar é só um passatempo. Ficou e passou. Fiquei e no outro dia já nem sei mais quem é." Ao citar isso, ela ressaltou que compreende que "atualmente é dessa forma que as pessoas se relacionam ao ficar".

Outra questão percebida durante as entrevistas foi com relação ao casamento e à redefinição dos papéis de homens e mulheres. Essa redefinição foi causada pela influência da primeira industrialização e da urbanização (Féres-Carneiro, 1998), que deram início a um processo de reorganização das tarefas, ao puxar as mulheres (primeiramente as das classes menos favorecidas) para o violento e brutal universo do mercado de trabalho e ao produzir o fenômeno das sufragistas, mulheres que, no início do século XX, lutaram, foram presas e morreram pelo direito de votar. Hoje a situação é outra. Percebe-se, a partir da fala do participante $A$, que tanto o homem quanto a mulher podem ser mais ativos, a mulher pode ser a fornecedora do dinheiro e quem paga as contas e, o cara pode ser quem cuida da casa. No sexo ela pode ser ativa, pode ser dominadora e o homem pode ser mais passivo. 
Ao ser questionada sobre os diferentes papeis desempenhados por homens e mulheres, a participante $H$ relatou que "eles podem desempenhar os mesmos papeis, sem exceção de nenhum". Já o entrevistado $\mathrm{E}$ trouxe um discurso um pouco diferenciado:

Não. Biologicamente são diferentes, culturalmente são diferentes também. Então é complicado você estabelecer isonomia com seres que desde a época das cavernas sempre foram diferentes. Por isso que se impõe a igualdade por livro, por lei é algo que já é diferente.

Essa fala remeteu a todo o processo histórico dos direitos adquiridos pela mulher ao longo do tempo. Já o entrevistado $B$ também trouxe um discurso relatando que na verdade isso é bem interessante, normalmente se tem uma visão de que o homem tem que tomar a iniciativa de tudo, de que cabe a ele iniciar qualquer ação dentro de um relacionamento. E não, pode também dividir um pouco essa responsabilidade.

Em outro momento da entrevista ele também mencionou a mudança dos papéis associada aos relacionamentos, afirmando: "eu estou percebendo uma inversão dos papeis, hoje em dia eu vejo mais homens querendo um relacionamento sério do que mulheres." Percebe-se aqui uma modificação da ideia romântica da mulher, que espera ser conquistada por um homem a fim de manter um relacionamento, bem como uma associação com o fato de que a mulher passa a ter relacionamentos sérios mais tarde por conta da dedicação à carreira profissional (Wendling, 2002).

Essa modificação dos papeis acabou por gerar mudanças nas famílias $\mathrm{e}$, inclusive no casamento. Atualmente, isso acaba por motivar os casais a viverem de uma maneira mais individualista, muitas vezes visando seu próprio prazer (Féres-Carneiro, 1998). Diante disso, pode-se compreender que os sujeitos passam a estipular projetos pessoais individuais. Essa concepção hedonista e que visa à satisfação dos prazeres individuais é percebida na fala do entrevistado $\mathrm{E}$, pois para ele os relacionamentos estão "voláteis. Nós vivemos em uma sociedade hedonista". Com relação a essas modificações percebidas no casamento, de acordo com a entrevistada $\mathrm{H}$.

(...) nunca existiu o tempo certo para casar. Tem os objetivos e prioridades, e principalmente a mulher anda fazendo isso, ela coloca a formação profissional e a vida independente a frente do casamento, isso tá pesando muito. Cada dia que passa a mulher tá ficando mais independente. 
Essa fala denota a mudança no papel desempenhado pelo casamento no imaginário feminino. Wendling (2002). Se, no paradigma romântico, a mulher ansiava pelo casamento que iria lhe garantir, além de amor e companhia, os proventos futuros advindos dos encargos decorrentes da maternidade, atualmente as mulheres passam a optar por casar e ter filhos mais tarde a fim de garantir seu futuro profissional.

Ao falar sobre o casamento, $F$ relata: "Eu diria que são as contingências do dia a dia que levam a pessoa a adiar ou acelerar". O entrevistado $\mathrm{E}$ ainda corrobora com a concepção geral de casamento dos demais participantes do grupo com idade entre 40 e 45 anos, afirmando que:

(...) o estágio que o capitalismo está não permite mais o casamento como foco das pessoas. O valor do casamento está bem atrás para as pessoas. Eles buscam algo a mais que o casamento, pelo menos a maioria delas. Há pessoas que ainda buscam o casamento, mas diminuiu bastante.

Diante desses relatos foi possível perceber que esse grupo de entrevistados trouxe uma concepção mais contemporânea sobre 0 casamento, não o atrelando mais a uma visão romântica, inclusive nos seus aspectos de eterno e duradouro, como também não o compreendendo como um dos principais projetos de vida. Esses fatores também foram percebidos nas falas de todos os entrevistados do outro grupo, que relatam, de uma maneira geral, que não existe tempo certo para casar, contudo há prioridades na vida que não são necessariamente o casamento.

E então chegamos no polêmico e inescapável problema levantado pelos aplicativos móveis de relacionamentos. Curiosa e ironicamente, os próprios aplicativos são designados móveis, uma vez que mobilidade é mesmo o cerne da questão. Esse tema acaba por ressaltar um tópico essencial aos dias de hoje, a conectividade. Bauman (2004) afirma que, desde que as pessoas estejam com seus celulares, elas nunca estarão fora ou longe, pois os celulares funcionam como uma extensão do corpo para esses sujeitos que estão em constante movimento e sempre conectados.

É a partir desse contexto que os aplicativos de relacionamento surgem, proporcionando aos sujeitos que, a partir de seus celulares, se conheçam e se relacionem de diversas maneiras com outras pessoas. Atualmente há vários aplicativos com esta função, como por exemplo: Happn, Kickoff, DateMe, Badoo e Tinder, sendo este último um dos mais utilizados e o trabalhado mais diretamente nesta pesquisa. Bauman (2004) ressalta que essa pseudo-proximidade acabou por tornar as conexões humanas mais frequentes e banais, pois, além de poderem ser encerradas somente a partir de um botão, 
elas não deixam sedimentos permanentes após seu término, concepção que denota ainda mais a fragilidade dos laços humanos na contemporaneidade.

Durante as entrevistas, podem-se perceber compreensões bastante diversificadas sobre o tema. B afirma:

Não digo relacionamento, mas conhecer uma pessoa pela internet é interessante. Até hoje em dia que tá todo mundo online fica mais fácil de encontrar alguém na internet do que na própria real life, no método convencional, digamos.

O fenômeno da troca entre os mundos "real" e "virtual", em que muitas vezes o segundo passa a ter preponderância sobre o primeiro, pode ser percebido nesta fala do entrevistado B. A entrevistada D também teve um relato que aponta uma proximidade com a realidade virtual. Segundo ela:

(...) é um aplicativo [Tinder], para mim, como qualquer outro desses amorosos. Uma pessoa pode namorar alguém que conhece pelo Facebook, então pode namorar alguém que conhece pelo Tinder, é a mesma coisa. O Tinder é só um outro tipo de aplicativo, talvez mais direto, para pessoas que estão a procura.

Já os entrevistados do segundo grupo trouxeram uma fala que difere das do grupo anterior. Segundo o participante $E$, os relacionamentos online:

(...) são novas formas, né? Antigamente, há cem anos, você tinha uma relação à distância com cartas e com olhar, e isso já indicava algum tipo de relacionamento. Então é uma nova forma de como lidar com isso, preencher seu espaço e seus vazios de diferentes formas inclusive com o uso dos aplicativos ou online: se isso traz felicidade para alguém, se é suficiente, então acredito que seja válido.

Nesse caso é possível perceber que o entrevistado tem um discurso positivo sobre os aplicativos de relacionamento, tratando-os como uma adaptação moderna das formas de lidar com as relações e vínculos. Contudo, é importante ressaltar que esse participante não citou especificamente nenhum aplicativo online, como também não sabe ao certo como funciona o Tinder. Já a entrevistada $G$, relatou uma compreensão bastante diferente do fenômeno:

Cara, eu entrei nesse Tinder. Mas, o pessoal só quer sexo! Não querem um relacionamento, aí eu "ah, quer saber, não é minha 
praia!" e saí. Mas, ali eu percebi que é como se fosse uma cartela em que você fica escolhendo o sabor que quer.

Já o entrevistado $\mathrm{F}$ afirma que "eu vejo que é só a primeira etapa, tem que ter a segunda etapa que é o pessoalmente. Quando vem a segunda etapa e você conhece pessoalmente é possível fechar o compromisso." A partir dessas últimas falas, compreende-se que os participantes do segundo grupo não mantém a mesma relação de naturalidade com os aplicativos online que os do primeiro grupo. Eles mostraram-se, inclusive, um pouco incomodados com 0 funcionamento deste e deram maior importância ao convívio pessoal. É interessante ressaltar que para eles, diferente de como foi citado por $B$, a real life não se encontra na internet, inclusive quase todos não acreditam na possibilidade de um relacionamento surgir e se consolidar por meio desses aplicativos. Esse fato foi citado por $\mathrm{H}$ ao relatar que "eu não acho legal. Eu não confio nesses relacionamentos" e por G: "Mas, acho que é como se fosse uma roleta russa, é um entre mil".

Finalizando as análises grupais, o último tópico a ser trabalhado refere-se ao amor e à felicidade. Neste tópico, não houve nenhuma discordância entre os participantes.

Ao se indagar sobre o propósito e finalidade de vida dos seres humanos, Freud (1939/2013) reitera que "é difícil errar a resposta: eles aspiram à felicidade, querem se tornar felizes e assim permanecer" (p. 62). Essa força de propulsão que impele o homem a ser feliz é denominada de "princípio do prazer", e visa produzir prazer ou evitar o desprazer do sujeito. Contudo "todas as disposições do universo o contrariam; seria possível dizer que o propósito de que 0 homem seja 'feliz' não faz parte do plano da criação' (Freud, 2013, p. 62-63).

Assim, para o autor, a felicidade é um fenômeno episódico de súbita satisfação de necessidades (1939/2013). Contudo, esse obstáculo não impede o homem de ter a felicidade como objetivo de vida (Sewaybricker, 2012).

De acordo com Bauman $(2008 ; 2009)$ a felicidade é ilusória, uma vez que há o constante empreendimento de novas promessas a fim de superpor as decepções. Assim é perpetuada a crença nessa constante busca. Essa promessa de felicidade que ocorre na vida liquidomoderna não se confirma, pois o deslumbramento ocorre na objetivação de satisfação. Diante disso, quando há uma vontade adquirida, cria-se uma nova. Essa concepção revela uma proximidade com o que Freud situou ser a felicidade. Já para Lipovetsky (2007), na forma do gozo incessante e na posse de bens de consumo, a felicidade impossível e paradoxal tornou-se um imperativo de euforia, adrenalina e adição. 
De acordo com Freud (1939/2013), "uma das manifestações de amor, o amor sexual, nos proporcionou a mais intensa experiência de uma sensação avassaladora de prazer, fornecendo-nos assim o modelo de nossas aspirações de felicidade (p. 74)". A realização da felicidade mantém uma relação com a "satisfação do fato de amar e ser amado (p. 74)". É possível perceber isso através da fala da participante $D$, ao relatar que "o amor complementa sua felicidade. $O$ amor é a felicidade para mim", como também pelo discurso do entrevistado $F$, dizendo que "a pessoa se sente feliz todos os dias se ela tem certeza que está amando outra pessoa, ela se sente feliz até para enfrentar os desafios do dia-a-dia".

Para Bauman (2004) os sujeitos amam o fato de poderem ser "objetos dignos de amor" (p. 100), de serem assim reconhecidos, bem como receberem a prova disto, de serem vistos pelo próximo como quem porta "um valor singular, insubstituível e não descartável" (p. 101). Isso já é percebido pela fala da participante G: "ele [o amor] traz alegrias, realizações. O amor traz um companheiro ou uma companheira para construir uma família juntos e tudo isso é felicidade" e pela fala da entrevistada C, afirmando que "você se sente melhor, se sente amada". Contudo, e paradoxalmente, o ser humano nunca se encontra tão desprotegido do sofrimento do que quando está amando, tornando-se infeliz quando perde o objeto amado ou seu amor (Freud, 1939/2013).

A participante $\mathrm{H}$ afirma que "se o amor for correspondido, traz felicidade sim". Bauman (2004) diz que "o amor é uma hipoteca baseada num futuro incerto e inescrutável" (p. 23). Seja como for, ao que parece e mesmo com toda a fluidez da modernidade líquida e dos relacionamentos instantâneos, ainda surge a possibilidade de felicidade em um encontro amoroso autêntico com o outro, com todas as incertezas que ele apresenta. O amor, mesmo que não seja eterno ou duradouro, ainda parece ser forte presença no imaginário contemporâneo.

\section{Considerações Finais}

O amor, talvez o tema mais presente em toda a história da arte e da literatura universal e um dos mais discutidos na filosofia é, possivelmente, também o mais complexo e paradoxal. Se hoje vivemos o fenômeno dos relacionamentos efêmeros, muitas vezes movidos a aplicativos e mensagens de celular e turbinados pelas páginas das redes sociais e dos chats de relacionamento, não podemos esquecer que o fenômeno já se apresentou sob formas muito variadas ao longo de nossa história. Já foi visto como irrelevante, quando os casamentos eram arranjados pelas famílias patriarcais, já foi visto como troca de bens por antropólogos 
estudando outros povos, já foi visto como o mais importante de tudo, sob a égide do paradigma romântico. Já foi chamado por Camões (1560/2001) de "contentamento descontente", "fogo que arde sem se ver" e "ferida que dói e não se sente". Neste mesmo soneto, o bardo português o afirma ainda um "andar solitário entre a gente". Todas estas frases denunciam seu caráter paradoxal e contraditório, o que também se evidencia no verso de Vinicius sobre sua duração infinita e efêmera. A mesma paradoxalidade e complexidade do fenômeno foi encontrada ao longo desta pesquisa. Amar é tentar vencer a inexorável solidão a que estamos todos, desde que nos cortaram o cordão umbilical, irremediavelmente lançados, uma busca aventureira que ninguém sabe se irá ou não dar bons frutos.

Quanto às mudanças na forma de se dar dos relacionamentos na contemporaneidade, percebe-se que, em alguns aspectos, houve uma notável diferenciação em relação a nosso passado recente. Lembrando que as conclusões aqui não podem ser universalizadas, dado se tratar de uma pesquisa de escopo reduzido e dadas as particularidades dos relacionamentos, que variam enormemente de um caso para outro, apontamos algumas tendências que apareceram, principalmente quando buscamos comparar os dois grupos pesquisados.

Quanto à estruturação dos relacionamentos amorosos, sua duração e frequência, concluímos que o primeiro grupo denota as transformações ocorridas com mais naturalidade. O segundo grupo, embora demonstre compreender a tendência atual, acaba por apresentar certa nostalgia do vínculo criado pelo amor romântico.

Contudo, ao se falar sobre a redefinição dos papeis de homem e mulher bem como do casamento, percebe-se uma maior proximidade entre os grupos. De maneira geral, para ambos os grupos a mulher e o homem podem desempenhar os mesmos papeis na relação amorosa e sexual. Com relação ao casamento, todos falaram que não há tempo estipulado para casar e corroboraram com o fato de que, na contemporaneidade, sob a égide do sistema capitalista global e altamente competitivo, as pessoas acabam estipulando outras prioridades, principalmente a carreira e, por conta disso, o casamento fica relegado a um segundo plano.

No que diz respeito aos aplicativos de relacionamentos, o primeiro grupo mostrou-se bastante familiarizado com seu uso e objetivo, acreditando ser normal conhecer alguém pelo Tinder ou pela internet, chegando ao radicalismo de afirmar que esta é a 'real life'. Já os integrantes do segundo grupo, via de regra, mostraram uma compreensão consideravelmente diferente desse aspecto, pois relataram se sentir incomodados com esses aplicativos, acreditando ser difícil um relacionamento verdadeiro surgir através destes e priorizando o convívio pessoal. 
Por fim, com relação ao amor e à felicidade, todos os participantes relataram que este é fonte de felicidade, contudo também concordaram que pode ser fonte de sofrimento se não for correspondido, corroborando com a teoria proposta para a análise.

Percebe-se que as compreensões entre os grupos ainda foram bastante similares em alguns pontos. Esse fato pode ter ocorrido por conta da escolha da idade dos sujeitos participantes. Possivelmente maiores contrastes teriam sido encontrados se tivessem sido incluídos entrevistados da faixa entre 60 e 65 anos.

\section{Referências}

Bardin, L. (2012). Análise de conteúdo. São Paulo: Edições 70.

Barthes, R. (2003). Fragmentos de um discurso amoroso. São Paulo: Francisco Alves.

Bauman, Z. (1998). O mal-estar da pós-modernidade. Rio de Janeiro: Zahar.

Bauman, Z. (2001). Modernidade Líquida. Rio de Janeiro: Zahar.

Bauman, Z. (2004). Amor Líquido: sobre a fragilidade dos laços humanos. Rio de Janeiro: Zahar.

Bauman, Z. (2008). Vida para consumo: a transformação das pessoas em mercadoria. Rio de Janeiro: Zahar.

Bauman, Z. (2009). A arte da vida. Rio de Janeiro: Zahar.

Benjamin, W. (1994). O narrador: considerações sobre a obra de Nikolai Leskov. In W. Benjamin, Magia e técnica, arte e política: ensaios sobre literatura e história da cultura. (pp. 197-221) São Paulo: Brasiliense.

Borges, M. L. (2004). Amor. Rio de Janeiro: Zahar.

Camões (1560/2001) Sonetos de Camões: sonetos redondilhas e gêneros maiores. São Paulo: Ateliê Editorial.

Caregnato, R. C. A. \& Mutti, R. (2006). Pesquisa qualitativa: analise de discurso versus analise do conteudo. Texto e Contexto de Enfermagem, 15(4), 679-684. Recuperado em 15 de novembro, 2015 de http://www.scielo.br/pdf/tce/v15n4/v15n4a17

Carelli, A.R. (2013). A sexualidade humana do passado ao presente. In Diehl, A.; Vieira, D.L. (Org.). Sexualidade: do prazer ao sofrer (pp. 01-38). São Paulo: Roca.

Carvalho, J. Q. (2010). As mutações no laço social amoroso na atualidade: uma discussão psicanalitica. Dissertação de Mestrado, Instituto de Psicologia, Universidade de Fortaleza, Fortaleza.

Chaves, J. C. (2001). "Ficar com": um novo código entre jovens. Rio de Janeiro: Revan Chaves. J. C. (2010). As percepções de jovens sobre relacionamentos amorosos na atualidade, Psicologia em Revista, 16(1), 28-46. 
Chaves, J. C. (2016). Praticas afetivo-sexuais juvenis: entre a superficialidade e o aprofundamento amoroso, Psicologia \& Sociedade, 28(2), 320-330.

Costa, J. F. (1998). Sem fraude nem favor: estudos sobre o amor romântico. Rio de Janeiro: Rocco.

Defleur, M. \& Ball-Rokeach, S. (1993) Teorias da comunicação de massa. Rio de Janeiro: Zahar.

Dela Coleta, A. S. M, Dela Coleta, M. F. \& Guimarães, J. L. (2008). O amor pode ser virtual? O relacionamento amoroso pela internet. Psicologia em Estudo, 13(2), 277-285.

Féres-Carneiro, T. (1998). Casamento contemporâneo: o difícil convívio da individualidade com a conjugalidade. Psicologia Reflexão e Critica, 11(2), 379-394.

Freud, S. (2006). Escritos sobre a Psicologia do Inconsciente (Volume I). Rio de Janeiro: Imago.

Freud, S. (2013). O mal-estar na cultura. Porto Alegre: L\&PM.

Gerhard, T. R., Ramos, I. C. A., Riquinho, D. L. \& Santos, D. L. dos. (2009). Estrutura do projeto de pesquisa. In: Gerhard, T. R. \& Silveira, D. F. (Org.). Métodos de Pesquisa (pp. 65-88). Rio Grande do Sul: Editora da Ufrgs.

Giddens, A. (1993). A transformação da intimidade: sexualidade, amor \& erotismo nas sociedades modernas. São Paulo: Unesp.

Goethe, W. (1774/2009). Os sofrimentos do jovem Werther. São Paulo: Editora Martin Claret.

Lipovetsky, G.(1989). O império de efêmero: a moda e seu destino nas sociedades modernas. São Paulo: Companhia das Letras.

Lipovetsky, G. (2007). A felicidade paradoxal: ensaio sobre a sociedade de hiperconsumo. São Paulo: Companhia das Letras.

Moraes, V. (1960). Antologia poética. Rio de Janeiro: Editora do autor.

Rand, A. (2002). A revolta de Atlas São Paulo: Arqueiro.

Rougemont, D. (2003). História do amor no Ocidente. Rio de Janeiro: Ediouro.

Sewaybricker, L. E. (2012). A felicidade na sociedade contemporânea: contraste entre diferentes perspectivas filosóficas e a Modernidade Líquida. Dissertação de Mestrado, Universidade de São Paulo, São Paulo, SP, Brasil.

Simmel, G. (1993). Filosofia do amor. São Paulo: Martins Fontes.

Schlosser, A. \& Camargo, B. Z. (2014). Contribuições de pesquisas brasileiras sobre o amor e relacionamentos amorosos, Temas em Psicologia 22(4), 495-808.

Testa, F. \& Figueiredo, T. (2013) Jovens tem até meta para beijar naboca em point na Festa do Peão, G1, Recuperado em 15 de março, 2015, de http://g1.globo.com/sp/ribeirao-pretofranca/festa-do-peao-de- 
barretos/2013/noticia/2013/08/jovens-tem-ate-meta-parabeijar-na-boca-em-point-na-festa-do-peao.html

Wendling, M. I. (2002). "Asas para voar, raízes para voltar": a saída dos filhos da casa dos pais. Dissertação de Mestrado, Instituto de Psicologia, Faculdade de Psicologia da PUCRS, Porto Alegre.

Zordan, E. P. (2010). A separação conjugal na contemporaneidade: motivos, circunstâncias e contextos. Tese de Doutorado, Instituto de Psicologia, Universidade Católica do Rio Grande do Sul, Porto Alegre.

\section{Endereço para correspondência \\ Marcio Acselrad}

Universidade de Fortaleza - UNIFOR

Avenida Washington Soares, 1321, Edson Queiroz, CEP 60811-905, Fortaleza - CE, Brasil

Endereço eletrônico: macselrad@gmail.com

\section{Rafaelly Rocha Lima Barbosa}

Universidade de Fortaleza - UNIFOR

Avenida Washington Soares, 1321, Edson Queiroz, CEP 60811-905, Fortaleza - CE, Brasil

Endereço eletrônico: psi.rafaellyrocha@gmail.com

Recebido em: $13 / 3 / 2016$

Reformulado em: 28/10/2016

Aceito em: 30/10/2016

\section{Notas}

* Professor Titular da Unifor - Professor Colaborador do Programa de PósGraduação em Psicologia da Unifor e do Programa de Pós-Graduação em Comunicação da Universidade Federal do Ceará. Graduado em Psicologia pela UFRJ, Mestre e Doutor em Comunicação pela UFRJ. Endereço de correspondência: Rua República do Líbano 961/901. Meireles. Fortaleza, Ceará, Brasil. CEP: 60140-160. Telefone: 85988987970.

** Graduada em Psicologia pela Unifor - Bolsista de iniciação científica do CNPq. Endereço de correspondência: Av. Benjamin Brasil, 1660. Maraponga, Fortaleza, Ceará, Brasil. Telefone: 85 98803.5738.

\section{APÊNDICE 1}

Roteiro de entrevista

1. Como você compreende os relacionamentos na atualidade?

2. Para você ficar é..?

3. Para você namorar é..?

4. Para você casar é...?

5. Você acha que é possível uma pessoa manter mais de um relacionamento serio ao mesmo tempo?

6. Sexo e amor andam juntos? Por que?

7. Qual sua concepção sobre pessoas que mantem relação de sexo casual?

8. Você acha que homens e mulheres podem desempenhar os mesmos papeis na relação amorosa e sexual?

9. O amor traz felicidade?

10. O sexo traz felicidade?

11. Você teria ciúmes do passado amoroso e sexual de seu (sua) companheiro (a)? 
12. Qual sua concepção sobre a mulher casar virgem?

13. Você falou sobre sexo com seus pais ou familiares?

14. Desejo é diferente de amor?

15. O que você procura em um relacionamento?

16. Por que você busca um relacionamento?

17. Você se sente seguro em um relacionamento?

18. O que você acha sobre relacionamentos online?

19. O que você acha do Tinder?

20. Você acha que as pessoas estipulam um tempo para casar? 